\title{
Factors Affecting the Migration of Juvenile Chum Salmon (Oncorhynchus keta) from the Coast of Hokkaido to the Okhotsk Sea
}

\author{
Tomonori Azumaya $^{1}$, Hiroshi Kuroda ${ }^{1}$, Tatuya Unuma ${ }^{1}$, Takashi Yokota ${ }^{1}$, and Shigehiko Urawa ${ }^{2}$ \\ ${ }^{1}$ Fisheries Research Institute, Japan Fisheries Research and Education Agency, 116 Katsurakoi, Kushiro, Hokkaido \\ 085-0802, Japan \\ ${ }^{2}$ Fisheries Research Institute, Japan Fisheries Research and Education Agency, 2-2 Nakanoshima, Toyohira-ku, \\ Sapporo 062-0922, Japan
}

Keywords: juvenile chum salmon, migration model, swimming speed

Japanese juvenile chum salmon (Oncorhynchus keta) migrate from coastal waters to the Okhotsk Sea during late spring/early summer. The Oyashio current flows southwestward off the Pacific coast of Hokkaido, while the Tsushima warm current flows northward off the Japan Sea coast (Fig. 1a). Thus, the migration direction of juvenile chum salmon is along the current off the Japan Sea coast, but opposite the current off the Pacific coast. In this study, factors affecting the migration of juvenile chum salmon from the Japan Sea coast and the east Pacific coast of Hokkaido to the Okhotsk Sea were investigated using a juvenile salmon migration model.

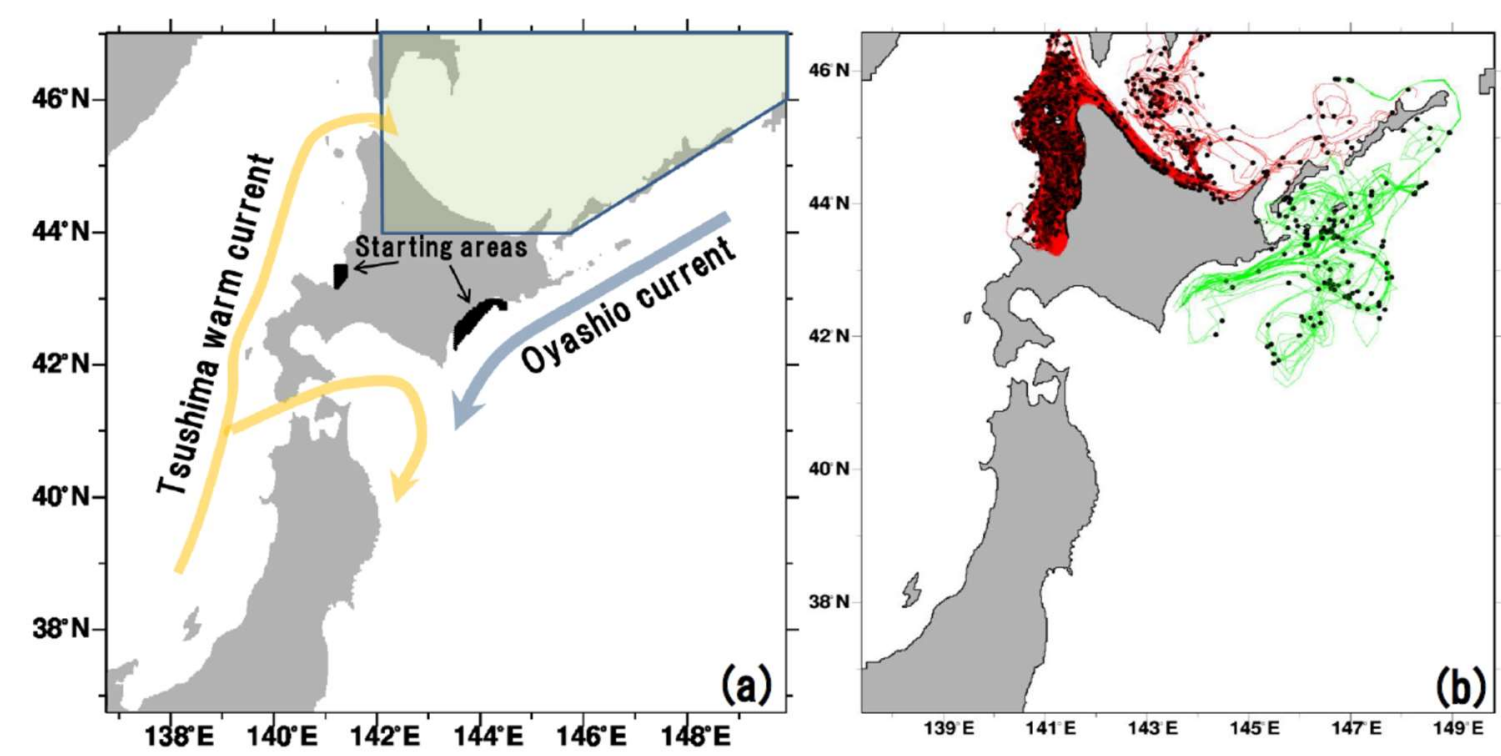

Fig. 1. (a) Schematic view of the current system around Hokkaido and the migration starting areas of juvenile chum salmon (black dots) in the migration model. The number of particles, which entered the hatch area in the Okhotsk Sea, was counted in the migration model. (b) Particle trajectories from the coast of the Japan Sea (red line) and the Pacific east coast (green line) of Hokkaido. Black circles indicate the positions of the particle at 10 days intervals. The particles from the Japan Sea are transported passively and particles from the east coast of the Pacific off Hokkaido are transported by active swimming.

The juvenile salmon migration model was driven by active swimming and passive transport by the currents which were the hydrodynamic model's outputs. In the migration model, particles were assumed to be juvenile chum salmon. The integrated period of the model was from March to August. Starting positions of the migration were in the Ishikari Bay along the Japan Sea coast of Hokkaido and the Pacific east coast of Hokkaido (Fig. 1a), and 44 particles from the coast of the Japan Sea and 134 particles from the Pacific east coast of Hokkaido were released every day during the model integration, respectively. The directions of active swimming and swimming speeds of juveniles were assumed to be opposite the current and the constant during the model integration. The migration routes and particle numbers that reached the Okhotsk Sea in $5 \mathrm{~cm} / \mathrm{s}$ swimming speed intervals from $5 \mathrm{~cm} / \mathrm{s}$ to 100 $\mathrm{cm} / \mathrm{s}$ were examined.

The juvenile chum salmon migration model reproduced the actual distribution of juvenile chum salmon off the Japan Sea coast of Hokkaido (Mayama and Ishida 2003) (Fig. 1b) (red lines). On the Japan Sea coast, juvenile

All correspondence should be addressed to T. Azumaya. 
chum salmon reached the Okhotsk Sea with passive transportation by the Tsugaru warm current. On the Pacific coast, juvenile chum salmon reached the Okhotsk Sea by their active swimming (Fig. 1b) (green lines). Particles released during the period of suitable water temperature range $\left(8-13^{\circ} \mathrm{C}\right)$ for juvenile chum salmon off the coast of the Japan Sea entered the Okhotsk Sea. As particles were released during the first half of the suitable water temperature period, particles experienced temperatures within the chum salmon habitat temperature range $\left(2.7^{\circ} \mathrm{C}-\right.$ $15.6^{\circ} \mathrm{C}$ ) from their release points to the Okhotsk Sea (Azumaya et al. 2007). Particles with a swimming speed of more than $35 \mathrm{~cm} / \mathrm{s}$, which were released from the Pacific east coast of Hokkaido, entered the Okhotsk Sea. With the increasing swimming speed, the number of particles that entered the Okhotsk Sea increased and the residence time became shorter (Fig. 2).

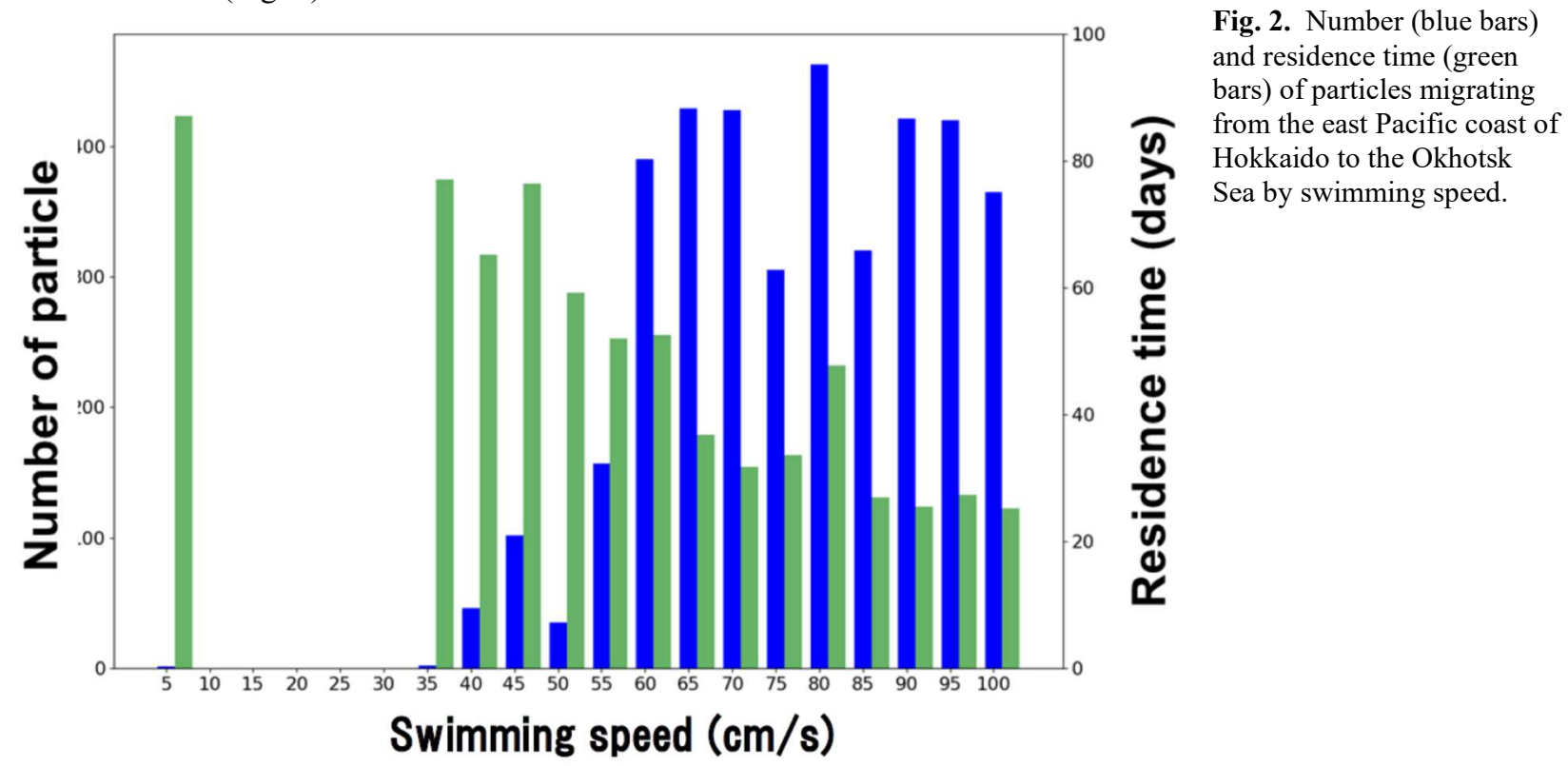

Juvenile chum salmon migrate from the Japan Sea coast to the Okhotsk Sea by passive current transport without dependence on their active swimming speed. Meanwhile, the active swimming speed affects the migration of juvenile chum salmon from the Pacific coast to the Okhotsk Sea. The results suggest that an important factor for successful migration and survival of juvenile chum salmon is release timing off the Japan Sea coast and the body size of released fry on the Pacific coast.

\section{REFERENCES}

Azumaya, T., T. Nagasawa, O.S. Temnykh, and G.V. Khen. 2007. Regional and seasonal differences in temperature and salinity limitations of Pacific salmon (Oncorhynchus spp.). N. Pac. Anadr. Fish Comm. Bull. 4: 179-187. (Available at https://npafc.org)

Mayama, H., and Y. Ishida. 2003. Japanese studies on the early ocean life of juvenile salmon. N. Pac. Anadr. Fish Comm. Bull. 3: 41-68. (Available at https://npafc.org) 